\title{
The Impacts of Relationship Property, Co-Production on Service Innovation Performance
}

\author{
Zhaoquan Jian, Yun Ke, Guangfa Wang \\ School of Business Administration, South China University of Technology, Guangzhou, China \\ Email: 18814110242@163.com
}

Received 27 February 2016; accepted 26 March 2016; published 29 March 2016

Copyright (C) 2016 by authors and Scientific Research Publishing Inc.

This work is licensed under the Creative Commons Attribution International License (CC BY). http://creativecommons.org/licenses/by/4.0/

(c) (i) Open Access

\begin{abstract}
This study is based on the theories of service Science, value co-creation theory and service innovation, combined with existing literatures to in-depth analyze the service innovation performance. This research draws samples from 161 services enterprises in Pearl River delta, adopting structural equations modeling (SEM), aiming to explore in depth that co-production and innovation orientation have mediating effect and moderating effect between relationship property and service innovation performance. The findings show that relationship property has a positive impact on service innovation performance. Co-production has a moderating effect between relationship property and service innovation performance. Innovation orientation demonstrates partly positive mediating effect toward relationship property and service innovation performance. Implications for research and managerial practices were discussed.
\end{abstract}

\section{Keywords}

Relationship Property, Co-Production, Innovation Orientation, Service Innovation Performance

\section{Introduction}

These service products are becoming more and more popular in the global market and create new opportunity of income increase for development of enterprises. Competition in service industry is fierce gradually in the process of globalization, which makes enterprises rethink their innovation ability and chances. Service innovation becomes an important means of adding value, retaining customers, developing market and growing for them. Therefore, current foremost task that attracts lots of attention is how to improve service innovation performance to promote the competitiveness of service enterprises.

How to cite this paper: Jian, Z.Q., Ke, Y. and Wang, G.F. (2016) The Impacts of Relationship Property, Co-Production on Service Innovation Performance. American Journal of Industrial and Business Management, 6, 305-314.

http://dx.doi.org/10.4236/ajibm.2016.63028 
Under pressure of intensifying competition, increasing labor cost and diversified customer demands, service enterprises also focus on possibility of external cooperation except for looking for innovation breakthrough from service products within the company. Customers act as participants in the process of service and have been widely put emphasis on and even have been regarded as "half of staff" [1]. Compared with technology-oriented manufacturing industry, service innovation stresses on customer orientation, customer is a more complicated and interesting role in service organization [2]. Cees and Fardad (2014) pointed out that when customers take part in absorption and effect combination of diversified knowledge to upgrade innovation, they also accelerate the cause of development activity [3].

Relationship property, co-production has important effect on the enterprises' service innovation performance. In recent years, some scholars have begun to investigate the relationship between the joint production and service innovation performance, such as Chen et al. [4], Ursula and Grissemaim et al. [5] had drawn similar conclusion that co-production had significant positive influence on service innovation performance, Tang et al. [6] studied the telecommunications industry, and found that customers co-production had significant positive influence on the market performance. However, the existing researches have the following questions: 1) previous studies on "innovation" are mainly concentrated on manufacturing industry but are rarely involved in service industry; 2) some studies just focused on direct affection of co-production on service innovation, lacked of intermediate mechanism discussion, especially the perspective of relationship attribute. In the study, starting from characteristics of service industry, framework of innovation performance of customers and service was constructed and analyzed, and questionnaire inquiry was performed in 161 service enterprises. Besides, experimental analysis was applied to explore influence of relation property, innovation orientation and co-production on service innovation performance. The research conclusion is helpful for understanding the role of customers in service innovation in a more comprehensive way and providing good reflection for service industry in the tough competition environment, and give guideline to enterprise about how to use co-production to improve service innovation performance.

This paper including five parts: 1) Introduction, in this part we will briefly introduce the research content and significance. 2) Theory and hypothesis, in this section we will review literatures and point out assumptions. 3) Research design, in this part we will introduce sample selection and data collection, the credibility and validity of data. 4) Data analysis and result, in this section we will verify the intrinsic relationship between each variable. 5) Research conclusion and reflection, which will point out the theoretical significance, practical suggestions and limitation of this paper.

\section{Theory and Hypothesis}

\subsection{Service Innovation Performance}

Since economics and management was introduced into innovation by Schumpeter, innovation has become the one of focuses for authors to discuss. Granovetter (1985) proposed that service innovation should be studied from the perspective of network and relation, for basic unit of network analysis was relation bond between movers, with the main idea that network members could transmit information, lore and resources among themselves to effectively explain and analyze process and result of service innovation [7]. According to 4D model of service innovation, service innovation could be concluded as intangibility, diversity, customer orientation and dynamic nature [8]. The paper hold that "customer orientation" caused by participation of customer in service production is obvious when enterprises and customers are in the network under the environment of co-production. Service innovation performance is affected by customers in network interaction to a large extent, while variables like relation property, co-production and innovation orientation are significant factors to determine whether communication between enterprises and customers is smooth or not.

Service innovation performance is an important component of service innovation. Voss et al. (1992) divided performance measurement of service innovation into measurement on process and result [9]. Storey and Kelly (2001) separated measurement indexes of service innovation performance into individual item level and planning level based on the concept of balanced score card (BSC) [10]. In the paper, depending on former scales, it was divided into performance of finance, market and inner.

\subsection{Relation Property}

Relation property is often regarded as the necessary factor of successful relation [11]. For products provided by 
enterprises is usually not real object, customers are faced with larger uncertainty, while the trust between enterprises and customers can reduce or remove this uncertainty. Lusch et al. (2010) pointed out that supply chain management and marketing had changed from the level that only paying attention to "article" model and intention to the wider model and intention, including service delivery and value creation. "S-D logic" (serviceoriented logic) highlights the improvement of "partnership” to service innovation value [12]. Yen and Gwinner (2004) proposed that establishment of relation with customers depends on strategy and executive force and preference of particular customers, and customers have a tendency to participate in “relation” [13].

It is noticeable that relation property has certain similarity with "relation quality" in connotation, but relation quality of service field put emphasis on service encounter result of both parties in the transaction relation [14]. While relation property focuses on interactive process state of enterprises and customers in cooperation, which is suitable for measurement in co-production. There are three dimensions in relation property: 1) affective commitment, measurement on emotion dependence between enterprises and cooperative partners, it can measure the effectiveness of emotional contract between two parties; 2) historical business relation, measurement on cooperative experience of enterprises and cooperative partners, involving two aspects, i.e. time and quality; 3) organization compatibility, measurement on degree of compatibility of enterprises and cooperative partners. These provide theoretical basis for us to study the impacts of relationship property, co-production on Service Innovation performance.

\subsection{Correlation between Relation Property and Service Innovation Performance}

In the theory of partnership of supply chain, Pittaway (2004) pointed out that it was mainly embodied in the following three aspects in the influence of positive relation property between enterprise and cooperative customer on service innovation value: development of potential market; sustainability of Innovation Promotion; decrease of risk control of innovation [15]. In the paper, there are mainly three dimensions, namely affective commitment, historical business relation and organization compatibility. In terms of affective commitment, authors put emphasis on significance of commitment in the process of development of cooperative agreement [16]. In the process of relation establishment, commitment is an important factor that affects success of cooperation [17]. For consciousness and affective preference has impact on cooperative relation, high affective commitment from partner can drive the other party to participate in cooperative innovation and achieve higher innovation performance. In terms of historical business relation, Chen (2011) said that both parties are familiar with each other based on certain cooperative history, and long-term continuous cooperation is always built on positive relation property [4]. Historical business relation discussed in the study mainly includes duration and stabilization of cooperative relation. In terms of organization compatibility, Bucklin and Sengupta (1993) proposed that organization compatibility is based on long cooperative relation and is related to intention of enterprise complementation and culture of cooperative partnership, the latter indicates that enterprises and cooperative partners attempt to enlarge cooperative relation by evaluating compatibility of important figures of both parties [18]. Cooperative partners with similar features tend to trust each other so that search and transaction cost among enterprises can be reduced. This means that the strong relationship property can lower the transaction cost of enterprises, thus prove service innovation performance.

Therefore, the paper proposes the following hypothesis:

$\mathrm{H} 1$ : Stronger the relation property is, more favorable the innovation performance is.

\subsection{Intermediation of Co-Production}

According to discussion of Vargo and Lusch (2004), value was mutually created by product/service supplier and customer and finally was determined by use value of customer. So customer is value receiver and cooperative producer [19] [20]. Dabholkar (1990) defined co-production of service as "degree for customer participating production and rendering service" [21]. In the previous literature of study on participation of customer in co-production, it held that productive profit of company can be made by customer participation and customer replacing labor of staff and operation of traditional limitation model for managing staff [22]. However, Ojasal (2009) thought that company could not freely regard customer as ordinary staff though they had opportunity to choose and cultivate customer [23]. Fundamental objective of customer is consumption rather production.

Thus, in the paper, it is more reasonable to regard customer participating in co-production of enterprise as "partner of enterprise”. Bucklin and Sengupta (1993) gave an opinion that in the case of strong organization 
compatibility, co-production of enterprise and customer is easier to realize [18]. Tether (2002) drew a conclusion on benefit of co-production of enterprise and customer as follows: providing complementary knowledge for enterprise and customer; achieving balance between service innovation performance and new product value; improving the acceptance of customer group for service innovation; reducing market risk undertaken by service innovation [24]. Co-production achieves value co-creation for enterprise and customer and promotes service value of enterprise and service innovation performance. Therefore, the paper proposes:

H2: Co-production plays mediating role in the influence of relation property on service innovation performance.

\subsection{Regulating Effect of Innovation Orientation}

Hurley and Hult (1998) defined innovation orientation as a kind of enterprise culture that accepting new things in an open way [25]. Innovation-oriented enterprises will actively seek for new opportunity instead of only applying existing advantages [26]. They attached importance to change and encourage adventure and creativity, and dared to bear risk when entering in new unknown areas. Siguawet (2006) held that innovation was embodied in multi-dimensional lore structure, including learning attitude, strategic direction, function compatibility and action, and can made both parties understand and execute innovation strategies and requirements of each other, and consequently promote the realization of innovation performance [27]. On the basis of establish a good relationship between partners, the right innovation orientation can improve enterprises' innovation service performance.

Based on above, the following hypothesis is proposed:

H3: Innovation orientation plays a regulating role in the influence of relation property on service innovation performance.

\section{Research Design}

\subsection{Sample Collection}

To sum up, the research framework is shown in Figure 1, where relation property is independent variable, co-production metavariable, innovation orientation regulated variable and service innovation performance dependent variable.

\subsection{Sample Selection and Data Collection}

Since service innovation is very important for service enterprises, object in this research survey and the questionnaire test is service-oriented enterprises in south China (Guangdong, Fujian province), especially those enterprises which take sales and service as the main revenue. The reasons why we choice these province as object are as fellow: Guangdong, especially the pearl river delta city is the gathering place of service enterprise, service enterprises develop rapidly, which make a great contribution to development of national economic; Xiamen is famous for its tourism industry, service industry develop well, what's more, Nation issued many policies to support the development of service industry in Xiamen in these two years. Therefore, these two provinces have strong representative significance.

The industries of these companies including finance, logistics, consulting, IT, communication, advertising, education training, tourism, health care and so on. According to the definition of services enterprises and service

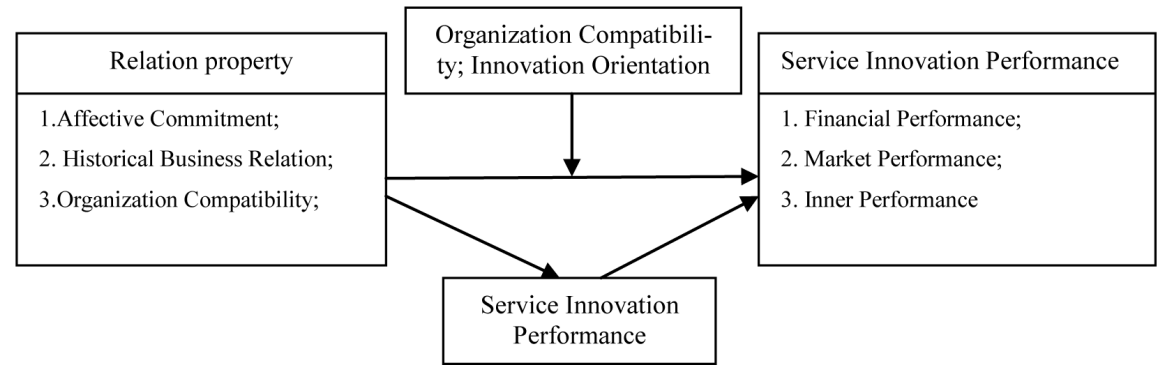

Figure 1. Research framework. 
co-production, Target object in the research is CEO of enterprise, vice manager of marketing and vice director of finance. These people are familiar with enterprise common production, innovation and service innovation, which can maximize ensure the accuracy and effectiveness of the survey. In order to avoid common method variance to capacity, two surveys were conducted successively in two years: 1) the first time was targeted at CEO and vice manager of marketing. CEO was mainly responsible for filling basic information of enterprise (age, scale, industry and district), innovation orientation of enterprise, while vice manager of marketing was in charge of evaluating relation property and co-production of enterprise; 2) the second time (one year later) was targeted at vice manager of finance evaluating organization innovation of enterprise.

Totally 432 complete enterprise samples were recovered in the first questionnaire. (CEO: 432, vice manager of marketing: 432). In the second questionnaire, 432 enterprises who gave complete information in the first time were issued questionnaires and totally 161 complete questionnaires filled by vice director of finance were recovered. After matching, 161 enterprises were taken as target objects. In the view of sample structure, average age of enterprises was 10.03 years, and $14 \%$ of them were equipped with less than 100 staffs, $34 \%$ with 100 500 staffs, $14 \%$ with 501 - 1000 staffs and 38\% with over 1000 staffs. In the view of regional distribution, $67.8 \%$ of enterprises were situated in Guang Dong, 32.2\% in Xiamen. The industry and area of these enterprises are shown in Table 1.

\subsection{Definition and Measurement of Operation of Variables}

In order to guarantee the efficiency and reliability of measuring tools, the paper tried to apply scales used in the domestic and overseas published literature. Before questionnaire was formally finalized and investigated, presurvey was performed on part of professors and businessmen and then questionnaire was appropriately modified according to suggestions given by subjects. Likert-type scale was applied in questionnaire design.

1) Relation property. In the paper, relation property was divided into three variables, namely affective commitment, historical business relation and organization compatibility. Scale of affective commitment and historical business relation applied Auh (2007) [28]; scale of organization compatibility is mainly based on measurement method given by Athaide and Stump (1999) [29], with 12 problems totally where 7 were the former and 5 were the latter.

2) Innovation Orientation. Innovation orientation refers to openness of new thought and change and tendency of application of new technology, resources and management system for enterprise and customer participating in service production link. Innovation orientation scale developed by Hurley and Hult (2006) measured the cultural tendency of enterprise to innovation [26]. Scale had high validity through testing, equipped with 6 problems.

3) Co-production. The paper divided it into 5 problems according to measurement method of "co-production" proposed by Chen [4] (2011).

(40) Service innovation performance. Scale of service innovation performance in the paper referred to study performed by Avlonitis, including 9 problems in three dimensions, i.e. financial performance, customer performance and inner performance [30] (2001).

\subsection{Analysis on Credibility and Validity}

Coefficient Cronbach $\alpha$ was applied in the study to verify the credibility of scale. If Cronbach $\alpha$ is over 0.7 , it

Table 1. Exploratory factor analysis result.

\begin{tabular}{|c|c|c|c|c|c|}
\hline \multicolumn{2}{|c|}{ Character description } & Index & Percentage (\%) & Index & Percentage (\%) \\
\hline \multirow{4}{*}{\multicolumn{2}{|c|}{ Industry }} & Finance & 8 & Advertising & 16 \\
\hline & & Logistics & 11 & Tourism & 5 \\
\hline & & IT & 29 & Consulting & 8 \\
\hline & & Communication & 9 & Others & 14 \\
\hline \multirow{4}{*}{ Area } & \multirow{3}{*}{$\begin{array}{c}\text { Guangdong } \\
(67.8 \%)\end{array}$} & Guangzhou & 23 & Huizhou & 6 \\
\hline & & Zhuhai & 10 & Shenzheng & 15 \\
\hline & & Zhongshan & 8.5 & Others & 5.3 \\
\hline & Fujian (32.2\%) & \multicolumn{4}{|c|}{ Xiamen (32.2) } \\
\hline
\end{tabular}


means that the factor has good intrinsic consistency. In the paper, consistency coefficient of relation property, innovation orientation, co-production and service innovation performance were respectively $0.786,0.844,0.856$ and 0.747 , and the total scale was 0.850 . It showed that sub-scale and total scale was possessed of good credibility.

In the paper, exploratory factor analysis and confirmatory factor analysis were applied to measure content validity and construction validity of measurement tool. KMO values of relation property, innovation orientation, co-production and service innovation performance were $0.636,0.783,0.874$ and 0.738 , and the significance probability in sphericity test was $0.000\left({ }^{* * *}\right)$ which meant that the effect was good and could be conducted further factor analysis. AMOS17.0 statistical software in the SEM theory was applied to conduct confirmatory factor analysis for data, mainly for goodness of fit test of model to verify whether various variables had sufficient convergent validity or not. Result shown in Table 2 showed that the questionnaire had good structure validity.

\section{Data Analysis and Result}

\subsection{Overall Model Building}

Figure 2 was established overall theoretical model. Z1, Z2 and Z3 represented centralized values of average of emotional commitment, historical business relation and organization compatibility under relation property; F1, F2 and F3 represented average of Q2.1 and Q2.2, Q2.3 and Q2.4, Q2.5 and Q2.6 of six problems under innovation orientation; Z1F1, Z2F2 and Z3F3 represented product terms. CY1, CY2 and CY3 represented centralized values of average of three indexes of service innovation performance. CQ3.1, CQ3.2, CQ3.3, CQ3.4 and CQ3.5 were centralized index values. SS1 and SS2 represented residual terms of service innovation performance and co-production, and index values in the model were all centralized. Latent variable was represented in ellipse, and observational variable was in rectangle.

Factor loading calculated from various paths through AMOS 8.0 was shown in Figure 2. Measurement errors of various indexes were all positive, and factor loading of measurement index of various latencies were all in the acceptable arrange, i.e. $0.5-0.95$, with a few possible exceptions $(\mathrm{Z3F} 3=0.484$, CY3 $=0.482)$ and reached significant level, which showed that this theoretical model followed preliminary fit criteria. It was shown in Table 3 that the degree of fitting of the model was good.

\subsection{Analysis on Path of Intermediation of Co-Production}

Influence result among variables can be divided into direct effect, indirect effect and total effect, where total effect is equal to direct effect plus indirect effect. It proposed that relation property had indirect effect on service innovation performance through co-production. The study proposed that relation property had indirect influence on service innovation performance through co-production and drew medium relational path from Figure 2 overall

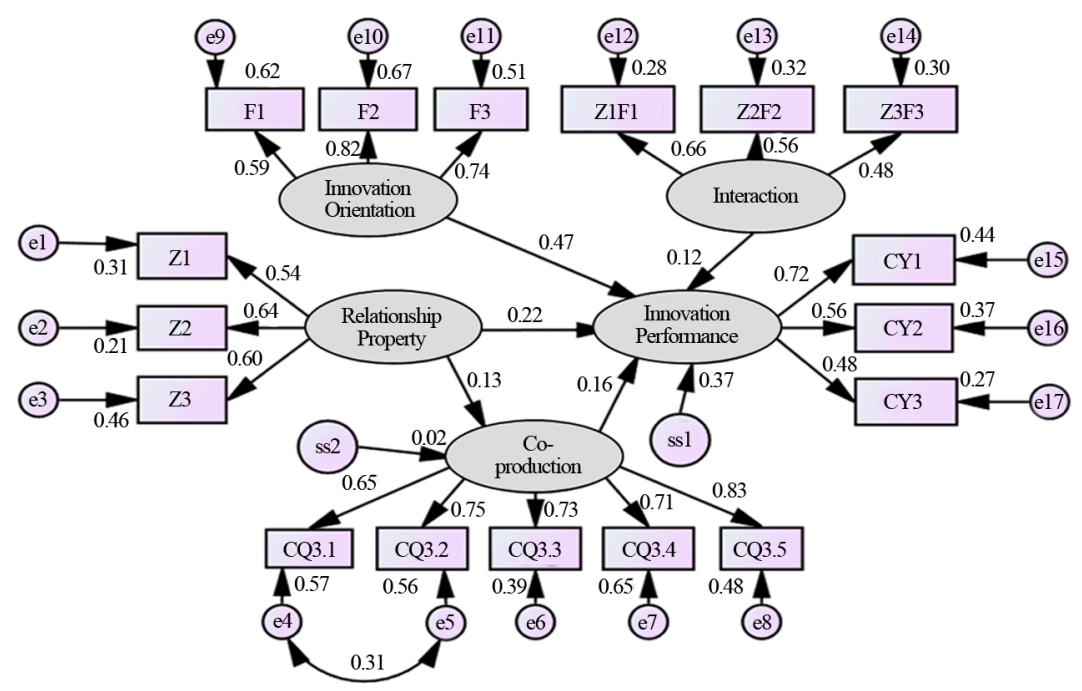

Figure 2. Overall structure model and path coefficient. 
Table 2. Exploratory factor analysis result.

\begin{tabular}{cccccccc}
\hline Fit index & $\chi^{2} / d f$ & GFI & CFI & TLI & RMR & RMSEA \\
Relation property & 1.432 & 0.889 & 0.912 & 0.898 & 0.043 & 0.035 \\
Innovation orientation & 1.556 & 0.846 & 0.892 & 0.853 & 0.048 & 0.021 \\
Co-production & 1.170 & 0.926 & 0.948 & 0.943 & 0.038 & 0.018 \\
Service innovation performance & 2.378 & 0.931 & 0.952 & 0.946 & 0.032 & 0.033 \\
\hline
\end{tabular}

\begin{tabular}{|c|c|c|c|c|c|}
\hline Index type & Fit index & Model evaluation & Index type & Fit index & Model evaluation \\
\hline \multirow{4}{*}{$\begin{array}{l}\text { Absolute fit } \\
\text { index }\end{array}$} & GFI & 0.892 & $\begin{array}{l}\text { Incremental } \\
\text { fit index }\end{array}$ & TLI & 0.925 \\
\hline & AGFI & 0.861 & \multirow{7}{*}{$\begin{array}{c}\text { Parsimony } \\
\text { fit index }\end{array}$} & AIC & 254.609 \\
\hline & RMR & 0.041 & & AIC & 317.000 \\
\hline & RMSEA & 0.049 & & AIC & 1117.603 \\
\hline \multirow{4}{*}{ Relative fit index } & CFI & 0.940 & & PNFI & 0.667 \\
\hline & IFI & 0.933 & & PCFI & 0.712 \\
\hline & NFI & 0.849 & & $x^{2} / d f$ & 1.545 \\
\hline & RFI & 0.814 & & - & - \\
\hline
\end{tabular}

theoretical model (Figure 3).

It was shown in the result that parameter evaluation of relation property and service innovation performance were all verified; among influence paths, effect size of pure standardization of relation property and service innovation performance was 0.393 ; path coefficient between co-production and service innovation performance was 0.288 ; standardized value of relation property and co-production was 0.109; all parameters attended significance testing. Through effect decomposition, direct effect of relation property to service innovation performance should be 0.393 ; mesomeric effect of co-production of metavariable should be $0.109 \times 0.288=0.0314$. Explanation: 1) relation property has significant and direct positive effect on service innovation performance; 2) relation property has significant and direct positive effect on co-production; 3) co-production has significant and direct positive effect on service innovation performance. Therefore, H1 and H2 were supported.

\subsection{Analysis on Path with Innovation Orientation Regulating Function}

It could be seen from previous research result that relation property and innovation orientation had significant effect on service innovation performance. In the study, three indexes were established for interaction between relation property and innovation orientation (Z1F1, Z2F2 and Z3F3), and all indexes are centralized. Regulating path effect was drawn from overall theoretical model (Figure 4). Figure 4 corresponded to the equation below:

$$
\eta=\gamma_{1} \xi_{1}+\gamma_{2} \xi_{2}+\gamma_{3} \xi_{1} \xi_{2}+\zeta \text {. }
$$

It was shown in Figure 4 that parameter evaluation of relation property and service innovation performance were all verified; among influence paths, effect size of pure standardization was of relation property and service innovation performance was 0.216 , and path coefficient of innovation orientation and service innovation performance was 0.129 , and all took significance testing. It showed that interaction of relation property and innovation orientation had direct positive influence on service innovation performance and supported H3 in the study.

\section{Research Conclusion and Reflection}

\subsection{Theoretical Significance of the Study}

In the study, inner mechanism of influence of relation property on service innovation performance was explored, and the result showed that 1 ) relation property has significant positive effect on service innovation performance; 


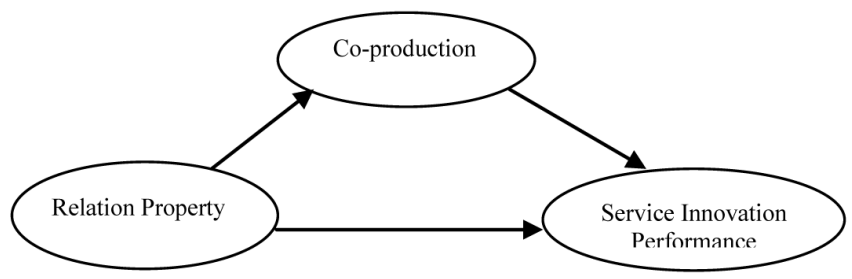

Figure 3. Path coefficient of mediation model.

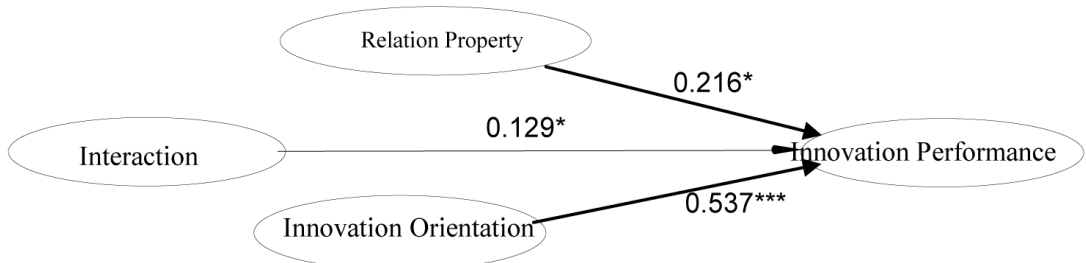

Figure 4. Path coefficient of regulating path model.

2) innovation orientation plays up-regulated role in the influence of relation property on service innovation performance; 3) co-production plays mediating role between relation property and service innovation performance. These studies expand existing recognition of mechanism of influence of relation property on service innovation. Theoretical contribution made in the paper was mainly embodied in:

1) Relation property is defined as "stability and consciousness tendency of relation established between customer and special retailer", i.e. key element that reflect relation between enterprise and customer, which is to measure interaction between both sides under co-production environment. Experimental analysis was conducted to reveal relation property measured by three independent variables, namely affective commitment, historical business relation and organization compatibility. It has significant positive effect on service innovation performance to concretely show path by which various dimensions of relation property can affect service innovation performance.

2) Influence of social interaction factors (customer, supplier, competitor, etc.) on service innovation in the process of service innovation was taken into account. In the study, co-production and innovation orientation were incorporated into the research on influence of relation property on service innovation performance and new model was built. Through experimental analysis, it found out that co-production plays partial intermediation role in the influence of relation property on service innovation performance, wherein intermediation was weaker than direction influence, and influence of innovation orientation on service innovation performance by regulating relation property in a positive way and effect of "innovation orientation" on service innovation performance by the means was replenished.

Although Chen et al. [4], Ursula and Grissemaim et al. (2012) had drawn similar conclusion that co-production has significant positive influence on service innovation performance [5], and Yao Shanji [31] (2015) and Yuan Ping [32] (2015) also figured out that customer participation has positive effect on service innovation in the study. However, these researches only pay attention on study on single variable but are lack of model that can reveal cause and effect. In the paper, influence model of relation property innovation orientation and that of co-production service innovation performance were established to systematically reveal that inner influence path and mechanism are of strong theoretical significance.

\subsection{Practical Significance of the Study}

The study is of great importance for innovation practice of enterprise service. Firstly, under increasing fierce competition stress, enterprises are limited by fighting alone to win in the competition while maintenance of positive relation property among customers has important influence on service innovation performance. For this purpose, cooperative enterprises should: 1) enhance affective commitment by necessary means of public relation; 2) get growing familiarity with each other and keep long and stable cooperative relation; 3) solve conflict and unbalance for cooperative organization in interaction to improve compatibility of cooperation organization and service innovation performance of enterprise. 
Secondly, starting from value network, co-production has become a part of value co-creation, and customer participation is vital variable that affects service innovation output. However, among sample enterprises, enterprises who really performance service innovation in co-production are not many for they believe "work behind closed doors" can satisfy the demand of pursuit of both parties for "efficiency" of service production, by contrast with "democratic" project. It explains that innovation effect of co-production on service innovation performance is less than that of relation property on service innovation performance. Given partial intermediation role of relation property, manager should not only improve relation property of customer, but also deeply explore potential demand of customer and give full play of merits of various parities by taking co-cooperation as executive means with service product.

In addition, for both cooperative enterprises with stable relation property, innovation orientation can guide strategy and action and help to achieve innovation performance. Because innovation orientation plays a regulating role in path of influence of relation property of enterprise and customer on service innovation performance, good relation property is insufficient, enterprises must adequately communicate with each other in the process of cooperation and make common target of service innovation and solidify this innovation intension to form an effective competitive strategy by following the development tendency of enterprise and to guide cooperative partners to realize complementary of resources and capability by depending on innovation orientation, and finally to improve service innovation performance of enterprises.

\subsection{Limitation}

Although this study reveals the relationships among co-production, innovation orientation properties and service innovation performance, it still exist some deficiencies: first, we choose China's Pearl River delta region, a service-oriented enterprise as research object, the universality of the results remains to be further validation in other areas. Second, the influence of relationship property on service innovation performance can't be observed in short time, some sample enterprises filled the questionnaire while their service innovation performance aren't fully revealed, which will cause data distortion. Finally, the mediation, adjustment paths among co-production, innovation oriented and service innovation performance are not very significant, maybe service innovation performance is also affected by other adjustments or mediation variables, which need us to do further research.

\section{References}

[1] Lengnick, C.A., Claycomb, V. and Inks, L.W. (2000) From Recipient to Contributor: Examining Customer Roles and Experienced Outcomes. European Journal of Marketing, 34, 359-383. http://dx.doi.org/10.1108/03090560010311902

[2] Li, Q.Z. and Xu, Z.X. (2014) The Influence Mechanism of Customer Co-production on Service Innovation Performance: An Empirical Analysis Basedon B2B Knowledge-intensive Business Service. China Soft Science, 8, 120-130.

[3] Cees, B. and Fardad, Z. (2014) R\&D Cooperation, Partner Diversity, and Innovation Performance: An Empirical Analysis. Journal of Product Innovation Management, 31, 292-312. http://dx.doi.org/10.1111/jpim.12096

[4] Chen, J.S., Tsou, H.T. and Russell, K.H.C. (2011) Co-Production and Its Effects on Service Innovation. Industrial Marketing Management, 40, 1331-1346. http://dx.doi.org/10.1016/j.indmarman.2011.03.001

[5] Ursula, S. and Nicola, E. (2012) Customer Co-Creation of Travel Services: The Role of Company Support and Customer Satisfaction with the Co-Creation Performance. Tourism Management, 33, 1483-1492.

[6] Tang, J. and Zhang, R.Z. (2012) Customer Participation in Service Innovation and its Performance Impact: An Empirical Research Based on Telecommunication Enterprises. Science and Technology Management Research, 20, 130-136.

[7] Granovetter, M.S. (1985) Economic Action and Social Structure: The Problem of Social Embeddedness. American Journal of Sociology, 91, 481-510. http://dx.doi.org/10.1086/228311

[8] Ren, L.C., Wu, C.H. and Wan, W.W. (2007) A Study on Co-Interaction between Knowledge Creation and Service Innovation Based on Alliance Network. Science of Science and Management of S\&T, 8, 54-58.

[9] Voss, C. (1992) Measurement of Innovation and Design Performance in Services. Design Management Journal, 12, 40-63.

[10] Storey, C. and Kelly, D. (2001) Measuring the Performance of New Service Development Activities. The Service Industries Journal, 21, 71-90. http://dx.doi.org/10.1080/714005018

[11] Berry, L.L., Shankar, V., Parish, J.T., Cadwallader, S. and Dotzel, T. (2006) Creating New Markets through Service Innovation. Sloan Management Review, 47, 56-63.

[12] Lusch, R., Vargo, S. and Tanniru, M. (2010) Service, Value Networks and Learning. Journal of the Academy of Mar- 
keting Science, 38, 19-31. http://dx.doi.org/10.1007/s11747-008-0131-z

[13] Yen, H.J.R. and Gwinner, K.P. (2004) The Impact of Customer Participation and Service Expectation on Locus Attributions Following Service Failure. International Journal of Service Industry Management, 15, 7-26. http://dx.doi.org/10.1108/09564230410523312

[14] Xu, J. (2010) The Impact of Project Relationship Quality on Project Performance-An Empirical Study Based on Construction Engineering Project. PhD, Chongqing University.

[15] Pittaway, L., Robertson, M., Munir, K., Denyer, D. and Neely, A. (2004) Networking and Innovation: A Systematic Review of the Evidence. International Journal of Management Review, 5/6, 137-168. http://dx.doi.org/10.1111/j.1460-8545.2004.00101.x

[16] Brennan, R. and Turnaull, P. (1999) Adaptive Behavior in Buyer-Seller Relationships. Industrial Marketing Management, 28, 481-495. http://dx.doi.org/10.1016/S0019-8501(99)00057-7

[17] Lancastre, A. and Lages, L.F. (2006) The Relationship between Buyer and a B2B Marketplace: Cooperation Determinants in an Electronic Market Context. Industrial Marketing Management, 35, 774-789. http://dx.doi.org/10.1016/j.indmarman.2005.03.011

[18] Bucklin, L.P. and Sengupta, S. (1993) Organizing Successful Co-Marketing Alliances. Journal of Marketing, 57, 32-46. http://dx.doi.org/10.2307/1252025

[19] Sorback, A.K. (1994) Developing Service Business Processes. Quality in Services Conference Proceedings, New Jersey.

[20] Vargo, S.L. and Lusch, R.F. (2004) Evolving to a New Dominant Logic for Marketing. Journal of Marketing, 68, 1-17. http://dx.doi.org/10.1509/jmkg.68.1.1.24036

[21] Dabholkar, P. (1990) How to Improve Perceived Service Quality by Improving Customer Participation. In: Dunlap, B.J., Ed., Developments in Marketing Science, Academy of Marketing Science, Cullowhee, 483-487.

[22] Mills, P.K. and Moberg, D.J. (1982) Perspective on the Technology of Service Operations. Academy of Management Review, 7, 467-478.

[23] Ojasalo, K. (2009) Designing Industrial Services-What Is the Role of the Customer? The Business Review, Cambridge, 14, 125-131.

[24] Tether, B.S. (2002) Who Co-Operates for Innovation, and Why: A Empirical Analysis. Research Policy, 31, $947-967$. http://dx.doi.org/10.1016/S0048-7333(01)00172-X

[25] Hurley, R.F. and Hult, G.T.M. (1998) Innovation, Market Orientation and Organizational Learning: An Integration and Empirical Examination. Journal of Marketing, 62, 42-54. http://dx.doi.org/10.2307/1251742

[26] Menguc, B. and Auh, S. (2006) Creating a Firm-Level Dynamic Capability through Capitalizing on Market Orientation and Innovativeness. Journal of the Academy of Marketing Science, 34, 63-73. http://dx.doi.org/10.1177/0092070305281090

[27] Siguaw, J.A., Simpson, P.M. and Enz, C.A. (2006) Conceptualizing Innovation Orientation: A Framework for Study and Integration of Innovation Research. Journal of Product Innovation Management, 23, 556-574. http://dx.doi.org/10.1111/j.1540-5885.2006.00224.x

[28] Auh, S., Bell, S.J., Mcleod, C.S. and Shih, E. (2007) Co-Production and Customer Loyalty in Financial Services. Journal of Retailing, 83, 359-370. http://dx.doi.org/10.1016/j.jretai.2007.03.001

[29] Athaide, G.A. and Stump, R.L. (1999) A Taxonomy of Relationship Approaches during Product Development in Technology-Based, Industrial Markets. Journal of Product Innovation Management, 16, 469-482. http://dx.doi.org/10.1016/S0737-6782(99)00011-9

[30] Avlonitis, G.J., Papastathopulou, P.G. and Gounaris, S P. (2001) An Empirically-Based Typology of Product Innovativeness for New Financial Services: Success and Failure Scenarios. Journal of Product Innovation Management, 18, 324-334. http://dx.doi.org/10.1016/S0737-6782(01)00102-3

[31] Yao, S.J., Lai, Y.J. and Jin, Y. (2015) Research on Driving Mechanism of Customer Participation on Enterprises’ R\&D Performance: A Perspective of Organizational Learning. Science of Science and Management of S\&T, 36, 95-104.

[32] Yuan, P., Liu, Y.B. and Li, X.S. (2015) The Relationship among Interaction Orientation, Customer Participated Innovation and Innovation Performance. Science Research Management, 36, 52-59. 